\title{
Increased prevalence of thyroglobulin antibodies in Sri Lankan schoolgirls - is iodine the cause?
}

\author{
L D K E Premawardhana, A B Parkes, P P A Smyth ${ }^{1}$, C N Wijeyaratne ${ }^{2}$, A Jayasinghe ${ }^{3}$, D G H de Silva ${ }^{4}$ and \\ J H Lazarus \\ Department of Medicine, University of Wales College of Medicine, Cardiff, UK, ${ }^{1}$ Department of Medicine, University College, Dublin, Ireland, and \\ Faculties of Medicine ${ }^{2}$ Colombo, ${ }^{3}$ Peradeniya and ${ }^{4}$ Galle, Sri Lanka \\ (Correspondence should be addressed to L D K E Premawardhana, Department of Medicine, Caerphilly Miner's Hospital, St Martin's Road, Caerphilly \\ CF83 2WW, UK; Email: ldkep@msn.com)
}

\begin{abstract}
Objective: Iodine deficiency was the likely cause of a high prevalence of goitre previously in Sri Lankan schoolchildren. Salt iodination was made compulsory in 1993 but there has been no recent study, using modern techniques, of its benefits or harmful effects.

Methods: Three hundred and sixty-seven schoolgirls between the ages of 11 and 16 years had ultrasound thyroid volume, free thyroxine (T4), free tri-iodothyronine (T3), thyrotrophin (TSH), antithyroglobulin $(\mathrm{TgAb})$ and thyroid peroxidase (TPOAb) antibodies, and urine iodine concentrations measured.

Results: Median ultrasound thyroid volume ranged from $4.8 \mathrm{ml}$ (11-year-old girls) to $8.6 \mathrm{ml}$ (16-yearold girls) with an age-related increase. Median urine iodine concentrations ranged from 105 to $152 \mu \mathrm{g} /$ 1. Free T4 and free T3 were normal in all, but TSH was elevated in four subjects $(5.53-41.29 \mathrm{mU} / \mathrm{l})$. However, the prevalence of $\mathrm{TgAb}$ was markedly raised, ranging between $14.3 \%$ (11-year-old girls) and $69.7 \%$ (16-year-old girls) $(P<0.03)$. In contrast, the prevalence of TPOAb was $10 \%$ or less in all age groups.

Conclusions: Normal median thyroid volumes, iodine concentrations and thyroid function would indicate that iodine deficiency is not a major problem in this group. The high prevalence of $\mathrm{TgAb}$, hitherto unreported, most likely reflects excessive iodination of $\mathrm{Tg}$ resulting in increased immunogenicity. There is an urgent need to continuously monitor the adequacy and risks of iodination in this population.
\end{abstract}

European Journal of Endocrinology 143 185-188

\section{Introduction}

The prevalence of goitre, estimated by palpation, was high in some parts of Sri Lanka (ranging between 6.5 to $30.2 \%$ ) in a survey conducted in 1987 (1). Anecdotal evidence suggested that iodine deficiency was the underlying cause, but features such as a very high prevalence in coastal towns has raised the possibility that other factors may have influenced goitre formation. Government legislation made salt iodination compulsory in 1993 and most commercially available salt is iodinated now to a variable degree (2). Such iodination, quite separately from its obvious benefits, may be potentially harmful, either by causing iodine-induced thyrotoxicosis (3) or by enhancing antibody production (4). As there are no recent data on urine iodine concentrations, thyroid ultrasound volume, and autoimmune and biochemical thyroid function in groups of subjects at risk of developing goitre in Sri Lanka, we undertook a study in female schoolchildren (chosen for their known higher prevalence of autoimmune markers and goitre compared with males) to examine the above, and to assess possible complications of salt iodination.

\section{Subjects and methods}

We examined 367 female schoolchildren between the ages of 11 and 16 years $(n=28-120$ in each age group), in six schools in three different regions of the country, chosen for their low, intermediate and high goitre prevalence rates as indicated in a previous study (1). The local ethics committee approved the project and the government and the schools involved granted permission for investigations on schoolchildren. A venous blood sample was collected for the estimation of free tri-iodothyronine (FT3), free thyroxine (FT4), thyrotrophin (TSH), thyroglobulin $(\mathrm{TgAb})$ and thyroid peroxidase (TPOAb) antibodies. These samples were 
centrifuged immediately and serum was stored in a freezer at $-20^{\circ} \mathrm{C}$. A random sample of urine $(20 \mathrm{ml})$ was collected for measuring iodine concentration and was similarly stored. These samples were transported to Cardiff and Dublin in secure, dry ice-filled containers and stored in a freezer at $-70{ }^{\circ} \mathrm{C}$. Thyroid ultrasound scans were performed by a single experienced investigator (PPAS) to eliminate inter-observer error. A portable ultrasound machine fitted with a $7.5 \mathrm{mHz}$ transducer (Siemens SL1, Erlangen, Germany) was used for the measurement of thyroid volumes (5). FT3, FT4 and TSH were measured on an automated immunoassay analyser, the ACS-180 Plus (Chiron Diagnostics Ltd, Halstead, Essex, UK). FT4 and FT3 were measured with competitive labelled antibody assays utilising an acridinium ester as label and paramagnetic particles as the solid phase, and TSH was by a two-site immunochemiluminometric assay. Normal values were as follows: FT3 4-6.8 pmol/l, FT4 $9.8-23 \mathrm{pmol} / \mathrm{l}$ and TSH $0.5-5.2 \mathrm{mU} / \mathrm{l}$. The between-batch precisions of the assays were as follows: FT4 (mean $13.6 \mathrm{pmol} / \mathrm{l}$ ), coefficient of variation (C.V.) $=4 \%$, FT3 (mean $5.27 \mathrm{pmol} / \mathrm{l}$ ), C.V. $=4.85 \%$ and TSH (mean $4.89 \mathrm{mU} /$ l), C.V. $=7.56 \%$. TgAb (normal $<98 \mathrm{kIU} / \mathrm{l}$ ) and TPOAb (normal $<19.4 \mathrm{kIU} / \mathrm{l}$ ) were measured by an ELISA technique standardised against the WHO Expert Committee on Biological Standardisation 1979 antithyroglobulin reference standard and NIBSC 66/387 anti-thyroid microsome serum respectively (both from the National Institute for Biological Standards and Control, London, UK (NIBSC)). The intra-assay variation for $\mathrm{TgAb}$ was $4.8 \%$ (mean $1350 \mathrm{kIU} / \mathrm{l}$ ) and for TPOAb it was $4.9 \%$ (mean $155 \mathrm{kIU} / \mathrm{l}$ ). The interassay variation for $\mathrm{TgAb}$ was $7.2 \%$ (mean $1387 \mathrm{kIU} / \mathrm{l}$ ) and for TPOAb it was $7.6 \%$ (mean $149 \mathrm{kIU} / \mathrm{l}$ ). A smaller random cohort of samples was assayed for $\mathrm{TgAb}$ using an immunoradiometric assay (Sanofi Diagnostics Pasteur, France). The between-assay precision was $5.8 \%$ (at $54 \mathrm{kIU} / \mathrm{l}$ ) and $3.3 \%$ (at $980 \mathrm{kIU} / \mathrm{l}$ ). Urinary iodine was measured using a manual method based on a modification of Barker's dry ash technique (6); results are expressed directly as $\mu \mathrm{g} / \mathrm{l}$ urine. The iodine content in eight samples of randomly collected commercially available salt was similarly analysed and expressed as parts per million (ppm).

\section{Statistical analysis}

Data were analysed using the Chi square or MannWhitney test as appropriate using the SPSS statistical package.

\section{Results}

Median thyroid ultrasound volume ranged from $4.8 \mathrm{ml}$ in 11-year-old children to $8.6 \mathrm{ml}$ in 16-year-old children with a consistent age-related increase. Fourteen subjects had a goitre (a prevalence rate of 3.8\%).
Median urine iodine concentrations varied between 105 and $152 \mu \mathrm{g} / \mathrm{l}$ and were comparable to values from iodine-sufficient areas.

Biochemical thyroid function was normal in 363 subjects and TSH was elevated in four subjects (range 5.53-41.29) with normal FT3 and FT4.

The prevalence of $\mathrm{TgAb}$ was elevated in all age groups: $14.3 \%$ in 11-year-old, $19.5 \%$ in 12-year-old, $44.1 \%$ in 13 -year-old, $53 \%$ in 14 -year-old, $52 \%$ in 15 -year-old and $69.7 \%$ in 16-year-old schoolchildren (Fig. 1). There was a statistically significant difference in the prevalence of $\operatorname{TgAb}$ when age groups at 11 and 12 years were compared with the rest $(P<0.03)$. The prevalence of $\mathrm{TgAb}$ in the higher age groups (13-16 years) was $48.2 \%, 63.2 \%$ and $53.5 \%$ in the areas with previous high, intermediate and low goitre prevalence respectively $(P<0.05$, high vs intermediate); and median urine iodine concentrations in the same areas were 136,130 and $112 \mu \mathrm{g} / \mathrm{l}$ respectively $(P<0.05$, high vs low). Overall, $\mathrm{TgAb}$ concentrations were minimally elevated (98-196 kIU/l) in 66\%, moderately elevated (196-392 kIU/l) in 23\% and highly elevated (>392 kIU/l) in $11 \%$ of antibody-positive subjects. The shift in the frequency distribution of TgAb between Sri Lankan schoolgirls and European adult females from a previous study (7) was statistically significant $(P<0.001)$. In order to eliminate the possibility of a falsely elevated prevalence of $\mathrm{TgAb}$ in Sri Lankan subjects due to a falsely raised baseline, TgAb concentrations were estimated in a random selection of samples using a different assay as detailed above. There was a significant correlation between the two methodologies $(r=0.76 ; P<0.001)$. In contrast to this rising prevalence in $\mathrm{TgAb}$, the prevalence of $\mathrm{TPOAb}$

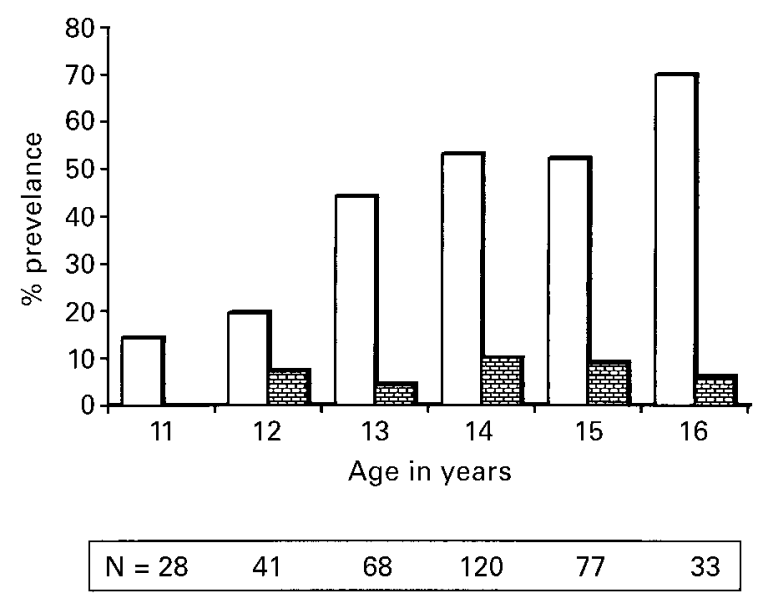

Figure 1 The prevalence of TgAb (open bars) and TPOAb (shaded bars) in schoolchildren between the ages of 11 and 16 years. There was a high prevalence of $\mathrm{TgAb}$ (with a significant difference in prevalence when 11- and 12-year-old groups were compared with the rest, $P<0.03$ ) and an age-related increase in the schoolchildren studied. TPOAb was detected at a significantly lower level of prevalence ( $\mathrm{N}=$ number of subjects in each age group). 
was $10 \%$ or less in all age groups and did not show an age-related increase (Fig. 1).

The iodine content in commercially available salt ranged from 0 to $33 \mathrm{ppm}$.

\section{Discussion}

This study has confirmed the absence of iodine deficiency and goitre in schoolchildren in three regions with previous low, intermediate and high goitre prevalence in Sri Lanka. These results are consistent with benefits of the salt iodination programme introduced by government legislation in 1993. Our data do not, however, exclude such problems in other parts of the country. The high prevalence of $\mathrm{TgAb}$ with an agerelated increase is an unusual phenomenon and, as far as we are aware, has not been shown before in a population-based study. However, control data were not available for comparison, as there have been no previous similar studies in this population. The thyroid antibody assays used were robust and reproducible (8), and there was a significant correlation between the two different techniques. The absence of a similarly high TPOAb prevalence makes assay interference extremely unlikely.

The prevalence of $\mathrm{TgAb}$ in schoolchildren in nonCaucasian populations is unknown, although rates up to $27 \%$ have been reported in adults (9). A high prevalence of both $\mathrm{TgAb}$ and TPOAb has been reported recently in Belarus children following radiation damage (10). The high prevalence of $\mathrm{TgAb}$ (compared with TPOAb) in our population is most likely due to enhanced iodination of $\mathrm{Tg}$ by iodine provided in salt (the iodine content of commercially available salt ranging from 0 to $57.6 \mathrm{ppm}$ (our own data and 2 ). $\mathrm{Tg}$ is an iodinated molecule and a template for thyroid hormone synthesis. There are experimental animal and human data to suggest that iodinated Tg is more highly immunogenic than poorly iodinated Tg (1113). There is an enhanced proliferation response of human $\mathrm{T}$ lymphocytes to iodinated $\mathrm{Tg}$, when compared with $\mathrm{Tg}$ lacking in iodine (11). In one study, $100 \%$ of mice given iodine-enriched water developed antibodies to $\mathrm{Tg}$, in contrast to controls that were deprived of iodine (12). Immunisation studies in chicken and mice confirm this impression (13). Clinical studies in iodine-deficient human subjects in Greece have also shown a higher prevalence of $\mathrm{TgAb}$ and TPOAb (with a higher prevalence of TPOAb) after 6 months of iodine supplementation (4).

The pathogenic significance of a high prevalence of $\mathrm{TgAb}$ in this population is unclear. A direct pathogenic role for $\mathrm{TgAb}$ in autoimmune thyroid disease has been suggested by restricted epitope recognition patterns and experimental autoimmune thyroiditis produced by passive transfer of $\operatorname{TgAb}(9)$. There is equally compelling evidence to suggest that the presence of $\mathrm{TgAb}$ is an epiphenomenon with no pathogenic significance (9).
Although the latter is likely in our subjects, the possibility of a high prevalence of $\operatorname{TgAb}$ being a marker of future autoimmune thyroiditis cannot be totally excluded.

The aetiology of previously detected high levels of goitre prevalence in Sri Lanka is difficult to elucidate on the basis of this study. The normal urine iodine levels (reflecting dietary iodine intake) in the schoolchildren studied (albeit with minor regional differences) indicate that dietary iodine is currently adequate, although previous iodine deficiency cannot be excluded. The use of modern techniques to measure thyroid ultrasound volume, urine iodine concentrations and thyroid autoimmune and biochemical status has improved the validity of these results in comparison with previously reported studies $(1,14,15)$. However, recent geochemical data suggest that iodine deficiency alone may not explain the pattern of goitre prevalence in the country. A link with selenium deficiency has been proposed (16).

The induction of autoimmune thyroiditis by iodine supplementation in previously iodine-deficient populations is a well-recognised phenomenon. This may occur in normal individuals and in subjects with underlying thyroid disease (3). There have been recent reports of possible iodine-induced thyrotoxicosis in Zimbabwe (17) and Zaire (18). However, the present study has not demonstrated any cases of iodine-induced thyrotoxicosis. Countries that adopt a policy of salt iodination should have mechanisms in place for monitoring the adequacy and unwanted effects of such iodination. The high prevalence of $\mathrm{TgAb}$ in this group of schoolchildren may herald the onset of an increased incidence of autoimmune thyroiditis with its own morbidity. We therefore recommend further studies and the establishment of a mechanism for monitoring the effects of iodination as urgent priorities.

\section{Acknowledgements}

The World Bank Office, Ministry of Health, Colombo provided funding for this study. The British Council, Colombo sponsored the travel arrangements of LDKEP, PPAS and JHL. We also wish to acknowledge the assistance provided in the planning of this study, in the field work and in the laboratory analysis of the samples, by the Principals, staff and pupils of the schools visited, and Dr Rhys John and Ms Lynn Taylor of the University Hospital of Wales, Cardiff.

\section{References}

1 Fernando MA, Balasuriya S, Herath KB \& Katugampola S. Endemic goitre in Sri Lanka. Asia Pacific Journal of Public Health 19893 11-19.

2 Kumarasiri JP, Fernandopulle BMR \& Lankathilake MALKN. Iodine content in commercially available iodised salt in the Sri Lankan market. Ceylon Medical Journal 1998 43 84-87.

3 Delange F. Correction of iodine deficiency: benefits and possible side effects. European Journal of Endocrinology $1995132542-543$. 
4 Boukis MA, Koutras DA, Souvatzoglou A, Evangelopolou A, Vrotakis M \& Moulopoulos SD. Thyroid hormone and immunological studies in endemic goitre. Journal of Clinical Endocrinology and Metabolism 198357 859-862.

5 Brunn J, Block U, Ruf G, Bos I, Kunze WP \& Scriba PC. Volumetric der Schilddrunsnelappen mittels real-time sonographie. Deutsche Medizinische Wochenschrift 1981106 1338-1340.

6 Foss O, Hankes LV \& Van Slyke DD. A study of the alkaline ashing method for determination of protein bound iodine in serum. Clinica Chimica Acta 19605 301-326.

7 Groves CJ, Howells RD, Williams S, Darke C \& Parkes AB. Primary standardisation of the ELISA of serum thyroid peroxidase and thyroglobulin antibodies and their prevalence in a normal Welsh population. Journal of Clinical and Laboratory Immunology 199132 $147-151$.

8 Lazarus JH, Parkes AB, John R, N’Diaye M \& Prysor Jones SG. Endemic goitre in Senegal - thyroid function, aetiological factors and treatment with oral iodized oil. Acta Endocrinologica 1992 126 149-154.

9 Tomer Y. Anti thyroglobulin autoantibodies in autoimmune thyroid disease; cross reactive or pathogenic ? Clinical Immunology and Immunopathology 199782 3-11.

10 Pacini F, Vorontsova T, Molinaro E, Kuchinskaya E, Agate L, Shavrova E et al. Prevalence of thyroid autoantibodies in children and adolescents from Belarus exposed to the Chernobyl radioactive fallout. Lancet 1998352 763-766.

11 Rose NR, Saboori AM, Rasooly L \& Bureck CL. The role of iodine in autoimmune thyroiditis. Critical Reviews of Immunology 199717 511-517.

12 Rasooly L, Bureck CL \& Rose NR. Iodine induced autoimmune thyroiditis in NOD-H-2h4 mice. Clinical Immunology and Immunopathology $199681287-292$.

13 Sundick RS, Bagchi N \& Brown TR. The role of iodine in thyroid autoimmunity; from chickens to humans - a review. Autoimmunity 199213 61-68.

14 Mahadeva K \& Senthe Shanmuganathan S. The problem of goitre in Ceylon. British Journal of Nutrition 196721 341-352.

15 Deo MG \& Subramaniam TAV. Iodine metabolism in women with endemic goitre in Ceylon. British Journal of Nutrition 197125 97105.

16 Fordyce FM, Johnson CC, Navaratne URB, Appleton JD \& Dissanayake JB. Studies of selenium geochemistry and distribution in relation to iodine deficiency disorders in Sri Lanka. British Geological Survey Technical Report 1998 WC/98/28.

17 Todd CH, Allain T, Gomo ZAR, Hasler JA, Ndiweni M \& Oken E. Increase in thyrotoxicosis associated with iodine supplements in Zimbabwe. Lancet 1995346 1563-1564.

18 Bourdoux PP, Ermans AM, Mukalay AM, Filetti S \& Vigneri R. Iodine induced thyrotoxicosis in Kivu, Zaire. Lancet 1996347 552-553.

Received 27 January 2000

Accepted 20 April 2000 